\title{
VII
}

\section{A NOTE ON CLIMATIC BUBO}

By H. M. Hanschell, D.S.C., L.R.C.P., M.R.C.S., D.T.M. \& H., Hon. Med. Supt. Seamen's Hospital, Royal Albert Dock, London.

INCREASING attention is now given to inguinal adenitis. In the tropics, and in the great seaports throughout the world, there is constant watchfulness for Bacillus pesiis infections; and lately the lesion commonly called climatic bubo has received frequent description and discussion, even to its exaltation as " the fourth venereal disease."

Climatic bubo is characterised by inflammation of the inguinal glands on one or both sides (and rarely the femoral glands also) and the tissues around them, usually accompanied by irregular fever. Redness and œedema of the skin varies : it may extend all over the inguinal region, or be confined to one or more patches over the glands. Suppuration is not extensive; here and there necrotic areas leading to sinus formation may appear. In size the swollen and matted-together inguinal glands may vary from walnut to orange. Often the smaller glandular enlargement is accompanied by the greater fever and invalidism.

The condition tends to become very chronic. Cases lasting many months and even a year are well known. The condition has been recorded, so far, only in males, and no second attack of climatic bubo has been noted. Most observers believe the infection to be acquired in the course of sexual union. But some patients afflicted with climatic bubo have denied coitus for five and six months before the inguinal lesion was noticed; and some few (young) males have denied any coitus at all.

In some cases a small shallow herpetiform ulcer about the glans penis may be seen, or the patient will state that two or three days after coitus he noticed such a lesion, which rapidly healed (it leaves no scar), and two weeks to two months later the glands in one of both groins became enlarged and painful. 


\section{CLIMATIC BUBO}

In very many cases when first examined some degree of balanitis is present.

The immensely greater prevalence of the bubo in the warmer climates accounts for the term " climatic." Though this is an easy and obvious, and socially convenient, qualification for a lesion usually acquired in copula, it may also have something of truth, for I have found, in the cases coming to the Seamen's Hospital, climatic bubo to be three times more frequent in engineer officers who work in very hot, very moist, atmospheres than among deck officers (and there are not three times more engineer than deck officers). The figures for

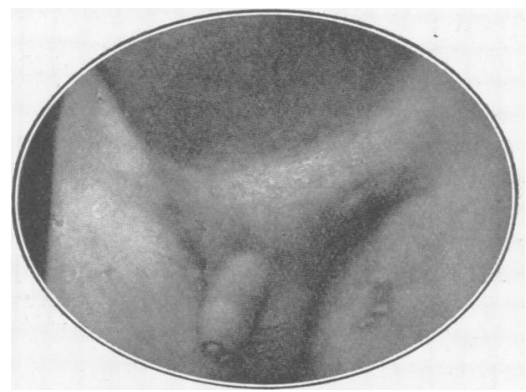

Left Climatic Bubo, present six weeks in a European seaman.

forecastle hands, stewards, and firemen show the proportion to be I:I:2.5 respectively. The fireman's work would place greater strain on the inguinal region, perhaps; he is still also more numerous than the other classes of seafarer.

Climatic bubo must be very rare in the circumcised.

Among the many Mahommedan Indian "Lascars" who have attended the Seamen's Hospital for diseases; venereal and other, most of whom are in fact firemen, during eight years, no case of climatic bubo has been seen, though many suffering from chancroid, with suppurating inguinal buboes, have been treated.

In contrast, climatic bubo has been seen among the prepuce-bearing white men, negroes, Chinamen, Japanese, and Christian Indian Goanese. It is not without a bearing on this point that among a circumcised indigenous populace, as in French North Africa, climatic bubo is commonly reported to be confined to the generally uncircumcised European newcomer.

Many attempts by many techniques, by many workers, 


\section{BRITISH JOURNAL OF VENEREAL DISEASES}

to isolate an organism from the glands have so far failed.

It is claimed that in section small round-cell infiltration is comparatively diminished in favour of an increase of large endothelial-cell-like proliferation. I have not found this histological characteristic constant, and have also seen it quite well marked in an inguinal gland inflamed as sequel to a typical chancroid on the penis.

In the glands small intracellular chromatin-like rods and dots may sometimes be observed in appropriately stained sections. Their significance is still in doubt.

Diagnosis of climatic bubo must rest on history, and exclusion of other causes of inguinal adenitis too well known to need enumeration.

Treatment.-(I) Rest in bed; (2) cleanse preputial sac with methylated spirit; (3) small collections of pus, if present, must be drained by sterile aspiration, repeated if necessary, the puncture point being sterilized and sealed off. It is important to avoid a secondary pyogenic infection. (4) Intravenous injection of killed typhoidgroup bacilli, beginning with Ioo million. This is usually followed by rigor, fever, sweat, and rapid resolution of the inguinal adenitis. It can be repeated in three or four days' time, increasing the dose to 200 million, and again to 300 million. It is very rare that a case needs more than three such injections. Usually this treatment enables the patient to be discharged in three or four weeks' time, a great contrast to the long bedridden illness that follows incision of the glands. This last invariably leads to secondary infection and more incisions, until the now deeply committed surgeon resorts to excision. All the glands, superficial and deep, are found to be involved, and all are extirpated. Healing is long delayed, and elephantiasis of penis or leg is a possible, and actually known, sequela. 